\title{
QUALIFICAÇÃO PROFISSIONAL NO PRONATEC E AS DEMANDAS DO NEODESENVOLVIMENTISMO LULO-PETISTA: formação voltada para a empregabilidade. ${ }^{1}$
}

\author{
Ricardo Afonso Ferreira de Vasconcelos ${ }^{2}$ \\ Mário Lopes Amorim³
}

\begin{abstract}
Resumo
Este artigo pretende realizar uma reflexão sobre a relação entre o ciclo de expansão econômica neodesenvolvimentista dos governos petistas de Lula e Dilma Rousseff e a redefinição da oferta de cursos de qualificação profissional por intermédio da criação e implementação do Programa Nacional de Acesso ao Ensino Técnico e Emprego (PRONATEC), criado no primeiro governo de Dilma, através da Lei no 12.513/2011, cujo objetivo seria garantir a expansão da formação profissional massiva de trabalhadores, atendendo as demandas de um suposto "apagão" de mão de obra qualificada. Prioriza-se a discussão envolvendo o perfil de qualificação presente nos cursos do PRONATEC.
\end{abstract}

Palavras-chave: Neodesenvolvimentismo; Qualificação Profissional; PRONATEC.

\section{Resumen}

Este artículo pretende realizar una reflexión sobre la relación entre el ciclo de expansión económica del nuevo desarrollo de los gobiernos petistas de Lula y Dilma Rousseff y la redefinición de la oferta de cursos de cualificación profesional por intermedio de la creación y implementación del Programa Nacional de Acceso a la Enseñanza Técnica y Empleo (PRONATEC), creado en el primer gobierno de Dilma, a través de la Ley $\mathrm{n}^{0} 12.513$ / 2011, cuyo objetivo sería garantizar la expansión de la formación profesional masiva de trabajadores atendiendo las demandas de una supuesta escasez de mano de obra cualificada. Se prioriza la discusión envolviendo el perfil de calificación presente en los cursos del PRONATEC.

Palabras clave: Neodesenvolvimentismo; Calificación profesional; PRONATEC.

\section{Introdução}

Este artigo pretende contribuir para a análise e avaliação do PRONATEC Programa Nacional de Acesso ao Ensino Técnico e Emprego, abordando os

\footnotetext{
${ }^{1}$ DOI: https://doi.org/10.22409/tn.16i30.p10090

${ }^{2}$ Doutor em Tecnologia e Sociedade (UTFPR). Docente do Instituto Federal do Pará (IFPA)Campus Belém. afonsoricardo2@hotmail.com

${ }^{3}$ Doutor em Educação pela USP. Docente do Programa de Pós-Graduação em Tecnologia e Sociedade (PPGTE) da UTFPR. marioamorim@utfpr.edu.br
} 
aspectos relacionados à sua gênese, estruturação e concepção. Considera-se o PRONATEC como uma alternativa formulada pelo Governo Federal para o atendimento da demanda de ampliação dos cursos de qualificação profissional dos trabalhadores, logo inserido no debate das políticas públicas de Educação Profissional.

O governo Lula ensejou uma importante mudança no modelo de relação entre a educação básica e a educação profissional, a partir do Decreto no $5.154 / 2004$. Este decreto possibilitou a sobrevivência da forma concomitante na Educação Profissional, e a partir da referida legislação foi concebido o PRONATEC no início do governo de Dilma Rousseff, como uma alternativa para o atendimento das demandas de força de trabalho exigidas pela nova fase de expansão econômica desenvolvimentista, desencadeada na gestão presidencial de Lula (2003-2010).

O texto inicia-se com uma caracterização do neodesenvolvimentismo nos governos petistas (2003-2016). Em seguida, relacionam-se os princípios norteadores do PRONATEC com os ditames das políticas neoliberais e da economia globalizada. Posteriormente, será analisado o PRONATEC enquanto programa de qualificação de trabalhadores, baseado na lógica da empregabilidade. Por fim, encerra-se o texto com as Considerações Finais.

\section{O neodesenvolvimentismo lulo-petista: desenvolvimentismo às avessas e reformismo fraco}

O Ministro da Fazenda Antônio Palocci, pertencente à corrente dos moderados do PT e com boa aceitação no meio empresarial e financeiro, tomou as seguintes medidas econômicas no início do primeiro governo Lula:

- $\quad$ Nomeou para o cargo de presidente do Banco Central o expresidente mundial do Bank Boston, Henrique Meirelles, mantendo, inicialmente, todo o restante da Diretoria anterior, em claro sinal de continuidade.

- $\quad$ Anunciou as metas de inflação para 2003 e 2004, de 8,5\% e $5,5 \%$, respectivamente, que implicavam um forte declínio em relação à taxa efetivamente observada em 2002, reforçando a política anti-inflacionária.

- Elevou a taxa de juros básica (Selic) nas reuniões do Comitê de Política Monetária (Copom), mostrando que isso não era mais um "tabu" para o PT. 
- Definiu um aperto da meta de superávit primário, que passou de 3,75\% para 4,25\% do PIB em 2003.

- Ordenou cortes do gasto público, para viabilizar o objetivo fiscal, deixando de lado antigas promessas de incremento do gasto [...] (GIAMBIAGI, 2011, p. 206-207).

Resumidamente, durante a gestão de Palocci no Ministério da Fazenda, prevaleceram as diretrizes de continuidade do processo de estabilização fiscal e monetária vigentes no governo de Fernando Henrique Cardoso (FHC). Todavia, a substituição de Antônio Palocci por Guido Mantega em 2006 no comando do Ministério da Fazenda representou uma importante mudança na condução dos rumos da economia do país, pois, segundo Giambiagi (2011, p. 215):

- [... a taxa de variação real do gasto público teve um aumento expressivo em relação à média dos dois primeiros anos de governo [...];

- $\quad[. .$.$] observou-se uma tendência a um afrouxamento dos$ superávits primários;

- [...] o Ministério da Fazenda passou a divergir claramente em várias ocasiões do Banco Central acerca da condução da política monetária;

- [...] foram abandonados os estudos que a área econômica vinha fazendo desde 2005, destinados a elaborar um plano de longo prazo visando maior contenção do crescimento da despesa, para atacar de modo mais vigoroso o desequilíbrio fiscal;

- $\quad[. .$.$] houve um aumento substancial da importância e do$ papel do BNDES na economia [...].

Porém, a grande mudança ocorrida durante a gestão de Guido Mantega se refere a intensificação da política de transferência de renda via programas governamentais, aliado ao forte estímulo ao consumo das famílias. Consequentemente, o "[...] consumo maior tornou-se a base do evidente sentimento de bem-estar da maioria da população e, por extensão, do eleitorado" (GIAMBIAGI, 2011, p. 221).

Efetivamente, durante o governo de Lula ocorreu uma recuperação do crescimento econômico e do investimento, proporcionando crescimento do emprego. Também o ajuste monetário e fiscal diminuiu a dívida líquida do setor público, e no plano externo "[...] as reservas atingiram 290 bilhões de dólares em 2010 e a dívida externa tornou-se negativa" (GIAMBIAGI, 2011, p. 229). Este novo cenário estimulou a crença de que o país estava retomando o caminho do crescimento econômico, fomentando o início do ciclo neodesenvolvimentista. 
Avaliando o ciclo neodesenvolvimentista lulo-petista, Bresser-Pereira (2015) considera que o governo do PT representou uma decepção, uma vez que não conseguiu concretizar a retomada do crescimento, apesar de ter propiciado a inclusão social e a redução do histórico processo de desigualdade social:

\begin{abstract}
Abria-se a oportunidade para que o desenvolvimento econômico fosse retomado, mas não foi isso que aconteceu. O governo do PT foi social-desenvolvimentista, mas, afinal, esse desenvolvimentismo malogrou: não logrou a retomada do desenvolvimento, nem logrou constituir uma coalizão de classes desenvolvimentista associando a burguesia industrial aos trabalhadores e à burocracia pública. Seu grande mérito foi o da inclusão social, que ocorreu graças ao forte crescimento do salário mínimo e à ampliação da política de transferência de renda; foi haver logrado a transferência de uma importante parcela da população para o consumo de massas, e, assim, reduzir a desigualdade existente no país (BRESSER-PEREIRA, 2015, p. 103).
\end{abstract}

O referido insucesso se deveu primeiramente a não resolução do problema do câmbio, uma vez que, "o governo Lula recebeu do governo anterior uma taxa de câmbio altamente depreciada (o que é uma benção), mas foi irresponsável ao deixar que ela se apreciasse nos oito anos de seu governo" (BRESSERPEREIRA, 2015, p. 103). O segundo motivo do malogrado desenvolvimentismo lulo-petista diz respeito ao crescimento vinculado à valorização das commodities, uma vez que:

Em seu governo houve um breve período de bom crescimento empurrado pelo aumento do preço das commodities exportadas (um boom), mas assim que os exportadores de manufaturados se organizaram para importar (o que demora em média três anos), as indústrias, que haviam deixado exportar no governo, mas ainda conservavam o mercado interno, o perderam para os importadores (BRESSER-PEREIRA, 2015, p. 104).

Apesar da retomada do crescimento econômico durante o governo Lula, ancorado especialmente pela expansão do setor de commodities, o estudo de Gonçalves (2013) sustenta a tese de que o processo de expansão econômica deste período correspondeu a uma modalidade de "nacional-desenvolvimentismo com sinal trocado", também denominado de "nacional-desenvolvimentismo às avessas", visto que a conduta do governo, o desempenho da economia e as 
estruturas de produção, comércio exterior e propriedade, caminharam no sentido contrário do modelo nacional-desenvolvimentista. Para Gonçalves (2013, p. 109), "[...] dentre os méritos ou pontos fortes do Governo Lula, não se encontram grandes transformações, reversão de tendências estruturais e políticas desenvolvimentistas". Ou seja, o NADA (Nacional-Desenvolvimentismo às Avessas) do referido governo manteve a desindustrialização, dessubstituição das importações, reprimarização, maior dependência tecnológica, desnacionalização, perda de competitividade internacional, crescente vulnerabilidade externa estrutural, maior concentração de capital e dominação financeira. Mas talvez o mais importante elemento componente desse desenvolvimentismo às avessas, segundo o referido autor, seja a tendência futura de maior vulnerabilidade da economia do país em relação ao contexto mais geral do capitalismo global:

Na medida em que o Governo Lula implementou o $\mathrm{MLP}^{3}$, ou seja, o $\mathrm{ND}^{4}$ com sinal trocado, reduziu-se a capacidade estrutural do Brasil de resistir às pressões, fatores desestabilizadores e choques externos [...]. Em consequência, lançou-se o país em trajetória de longo prazo de instabilidade e crise no contexto de crescente globalização econômica. Durante o governo Lula foram cometidos erros estratégicos que comprometem estruturalmente 0 desenvolvimento do país no longo prazo (GONÇALVES, 2013, p. 110).

O estudo de Alves (2014) a respeito do significado sócio histórico do neodesenvolvimentismo lulista considera-o como um novo padrão de expansão capitalista. Para Alves (2014) o ciclo neodesenvolvimentista da década de 2000, foi a expressão de uma modernidade hipertardia que substituiu o governo de tendência neoliberal de Fernando Henrique. Logo, a "eleição de Lula da Silva pelo PT significou a necessidade de construção de um modelo de desenvolvimento capitalista, não mais orientado pelos parâmetros neoliberais" (ALVES, 2014, p. 130-131). No entanto, na avaliação de Alves o governo de Lula foi incapaz de romper com o núcleo duro da economia neoliberal, e por isso manteve seus pilares, sinalizando já na época da campanha eleitoral de 2002, através da Carta aos Brasileiros, que se manteria alinhado com o bloco hegemônico no mercado mundial. Para este autor, "o objetivo do novo governo pós-neoliberal era

\footnotetext{
${ }^{3}$ Modelo Liberal Periférico.

${ }^{4}$ Nacional-Desenvolvimentismo.
} 
reorganizar o capitalismo no Brasil e não aboli-lo. Enfim, promover um choque de capitalismo nos moldes pós-neoliberais" (ALVES, 2014, p. 131).

Ainda segundo Alves (2014, p. 140), o neodesenvolvimentismo lulo-petista se apresentou como uma alternativa de projeto reformista hipertardio, no qual ocorreu o "amesquinhamento irremediável da ideologia socialdemocrata". Pragmaticamente tal neodesenvolvimentismo representou uma modalidade de reformismo fraco que promoveu um choque de capitalismo, buscando conciliar elementos de inclusão e exclusão inerentes ao desenvolvimento capitalista em nosso país:

[...] o neodesenvolvimentismo como reformismo fraco que impulsiona o choque de capitalismo, não deixa de conter o seu tom farsesco, uma dimensão trágica - ele impulsiona à exaustão, contradições vivas do desenvolvimento capitalista no Brasil. Por um lado, assume a tarefa histórica de combater a pobreza extrema e promover a inclusão do subproletariado no mercado de trabalho formal, realizando, deste modo, o sonho do consumo dos trabalhadores da massa marginal; por outro lado, preserva os pilares do modo de desenvolvimento social excludente do capitalismo histórico no Brasil incentivando a centralização e concentração do capital oligopólico na condição histórico-mundial da senilidade capitalista como modo de desenvolvimento civilizatório (ALVES, 2014, p. 140).

Em resumo, é possível afirmar que o modelo neodesenvolvimentista dos governos Lula e Dilma, apesar da retomada do crescimento econômico, constituiu-se numa espécie de "desenvolvimentismo às avessas", uma vez que não representou uma ruptura decisiva e efetiva em relação ao modelo neoliberal herdado dos governos de FHC.

\section{A lógica da economia globalizada e da hegemonia do Estado neoliberal regula as diretrizes das políticas públicas de educação e os paradigmas que norteiam o PRONATEC}

Quando examinamos as motivações econômico-sociais, políticoideológicas e institucionais que contribuíram para a concepção do PRONATEC, percebemos que, além das demandas por mão de obra qualificada ligada à fase de expansão econômica neodesenvolvimentista iniciada no governo Lula, concorreu para a concepção e implementação da referida política educacional as vinculações desta com a lógica hegemônica da globalização e dos princípios do 
Estado neoliberal. Logo, torna-se necessária a discussão em torno desses dois elementos reguladores das políticas públicas a partir de seus paradigmas.

As últimas décadas do século $X X$ viram surgir uma nova realidade socioeconômica no cenário mundial - a sociedade global. Com a globalização, ocorreram mudanças estruturais que afetaram diretamente o papel do Estado e também os paradigmas que nortearam a estruturação das políticas públicas de educação:

O Estado-Nação perde importância, novos espaços são desenhados, novas redes de poder são articuladas, novas racionalizações elaboradas, novas dialéticas surgem: o nacional, o regional, o local são colocados a serviço do novo modelo econômico global transnacional e transcultural (GAMBOA, 2009, p. 95-96).

O estudo de Gamboa (2009, p. 96) argumenta que a Globalização, ao mesmo tempo em que provoca o processo de esvaecimento do Estado-Nação, inversamente estimula o surgimento de "[...] um poderoso Proto-Estado-Global que representa os interesses da nova divisão de classes da sociedade global". Esta nova instância de poder no nível internacional apresenta elementos constitutivos tais como, "[...] o Conselho de Seguridade, O Grupo G-7, a OTAN", o GATT'6 , o $\mathrm{FMI}^{7}$, o BM ${ }^{8}$ etc." (STEFAN, 1995 apud GAMBOA, 2009, p. 96).

$\mathrm{O}$ fortalecimento do referido Proto-Estado-Global também se deu à custa da quebra das fronteiras nacionais. Neste novo cenário, "o dinheiro volátil ficou livre", bem como, o "[...] sistema financeiro internacional e o fluxo de capital financeiro emanciparam-se do controle dos bancos nacionais" (GAMBOA, 2009, p. 97.

O estudo de Teodoro (2011), focado essencialmente no tema da educação na atual fase da globalização de feição neoliberal, argumenta que os sistemas de educação de massa, iniciados na transição do século XVIII para o século XIX, ensejaram o perfil de uma escola que se tornou um espaço de "integração social e de formação para o trabalho" (TEODORO, 2011, p. 11). Sendo assim, surgiu o processo de massificação dos sistemas de educação, que conduziu a uma

\footnotetext{
${ }^{5}$ Organização do Tratado do Atlântico Norte.

${ }^{6}$ General Agreement on Tariffs and Trade. Em português: Acordo Geral de Tarifas e Comércio.

${ }^{7}$ Fundo Monetário Internacional.

${ }^{8}$ Banco Mundial.
} 
mudança na forma de escola, no sentido de escolarizar os jovens com dificuldades sociais ou de aprendizagem, o qual o referido autor denomina de "a escola para todos" (TEODORO, 2011, p.11-12).

Não obstante tenha representado um avanço no contexto das sociedades democráticas, o paradigma do sistema de educação de massas experimenta, na atualidade, uma dupla crise, que Teodoro (2011, p. 12) define como sendo:

[...] de regulação, porque não cumpre, em muitas situações, o seu papel de integração social e de formação para as novas exigências da "economia do conhecimento"; e de emancipação, porque não produz a mobilidade social aguardada por diversas camadas sociais para quem do status alcançado a frequência da escola, sobretudo nos seus níveis superiores, constituía o melhor meio de ascensão social, ou de reprodução.

O estudo de Teodoro (2011, p. 12) também indica que esta crise da escola envolve "baixos resultados escolares, deficiente inserção profissional e fraca capacidade de socialização" desembocando naquilo que o referido autor denomina de verdadeira "epidemia política" (BALL, 2000 apud TEODORO, 2011), qual seja: as reformas da educação, fenômeno que atingiu diversos países e governos, impulsionado por poderosos agentes econômicos, como por exemplo, a Organização para a Cooperação e Desenvolvimento Econômico (OCDE). Essas reformas da educação "[...] tornaram-se uma obsessão dos governos. Três palavras chaves passaram a dominar esse discurso reformador a partir dos anos 1990: competitividade, accountibility (prestação de contas) e performatividade" (TEODORO, 2011, p. 13).

A crise da escola, inserida no contexto da Globalização, remete à questão do papel que esta desempenha na nova divisão social do trabalho. Gamboa (2009, p. 98) sustenta que: "A educação, atrelada que está aos interesses dominantes na sociedade global, parece redefinir seu papel de formulador do homo faber para essa nova fase do capitalismo". Para tanto, é frequentemente reeditada a Teoria do Capital Humano.

A Teoria do Capital Humano, elaborada por Becker e Schultz no final da década de 1950, tornou-se uma ferramenta que serviu para ampliar o debate em torno da relação entre Escola e Capitalismo nas últimas décadas. Os teóricos 
ligados ao Capital Humano advogam a ideia de que investimentos em educação dão retorno em forma de benefícios individuais e sociais:

De acordo com a teoria do capital humano (SCHULTZ, 1962; 1973), o trabalho qualificado passa a ser capital acumulado e sua contribuição no processo produtivo é remunerada de forma correspondente àquela atribuída ao capital que participa do processo produtivo sob a forma de máquinas, equipamentos etc. assim, um trabalhador qualificado recebe mais, porque a sua remuneração, relativamente ao trabalhador não-qualificado, representa também o pagamento à contribuição do capital humano que o trabalho qualificado incorpora [...] Ao assumir uma suposta correlação direta e positiva entre desenvolvimento de salários e inversão em educação, a teoria do capital humano colocou em destaque a importância dos investimentos em educação e capacitação [...] (LIMA FILHO, 2003, p. 69).

Concernente ao vínculo entre educação, capacidade de trabalho e de produção, Frigotto (2003, p. 41) explicita de forma mais detalhada a lógica de fundamentação da Teoria do Capital Humano:

\begin{abstract}
A ideia-chave é de que a um acréscimo marginal de instrução, treinamento e educação, corresponde a um acréscimo marginal de capacidade de produção. Ou seja, a ideia de capital humano é uma "quantidade" ou um grau de educação e de qualificação, tomado como indicativo de um determinado volume de conhecimentos, habilidades e atitudes adquiridas, que funcionam como potencializadoras da capacidade de trabalho e de produção. Desta suposição deriva-se que o investimento em capital humano é um dos mais rentáveis, tanto no plano geral do desenvolvimento das nações, quanto no plano da mobilidade individual.
\end{abstract}

Frigotto (2003, p. 41) sustenta também que a "[...] disseminação da Teoria do Capital Humano, como panaceia da solução das desigualdades entre países desenvolvidos e subdesenvolvidos [...] foi rápida nos países latino-americanos e de Terceiro Mundo". Isto se explica pela ação de organismos internacionais, como por exemplo, BID, OIT, UNESCO, FMI, e também de organismos regionais, como o caso da CEPAL, sendo que tais organismos representam claramente a visão e os interesses do grande capital.

No Brasil, a Teoria do Capital Humano influenciou intelectuais da área econômica, tais como Mário Henrique Simonsen e Carlos Langoni. No caso de Simonsen, Frigotto (2003, p. 42) afirma que este "[...] pregava ao mundo que o Brasil tinha encontrado seu caminho para o desenvolvimento e eliminação das 
desigualdades [...] pela equalização do acesso à escola e pelo alto investimento em educação". Frigotto (2003) exemplifica o caso do MOBRAL, que foi a obra criada e deixada como legado de Simonsen.

No caso de Carlos Langoni, Lima Filho (2003, p. 70) destaca o estudo deste economista publicado em 1974, sob o título As causas do crescimento econômico do Brasil, no qual o referido autor "[...] analisa a correlação entre o nível de qualificação da força de trabalho e o crescimento econômico nacional no período entre 1940 e 1970 concluindo pela consistência dos pressupostos da teoria do capital humano [...]".

No que se refere à relação Estado-Neoliberalismo-Globalização, Teodoro (2011) elaborou o perfil do Estado Neoliberal a partir da análise feita por Harvey (2005), considerando que o neoliberalismo se assenta sobre as seguintes bases:

a) favorecimento do direito de propriedade; b) estímulo ao livre funcionamento dos mercados e do comércio livre; c) defesa da propriedade privada. Teodoro (2011) também argumenta que os teóricos do neoliberalismo nutrem uma desconfiança em relação à democracia, preferindo formas de organização de governo mais elitistas e restritivas de ampla base popular:

Em geral, preferem formas de governo conduzidas por elites e tecnocratas, baseadas em executivos fortes e em instituições autônomas da decisão democrática dos parlamentos, como o banco central e as instituições reguladoras. O direito e a lei, quando estão conformes seus interesses, têm um papel central na teoria neoliberal. Todas as soluções e remédios devem ser procurados, individualmente, no sistema legal (TEODORO, 2011, p. 63-64).

O estudo de Castanho (2009, p. 28), por sua vez, identifica posturas inerentes ao neoliberalismo, diretamente vinculadas ao advento do capitalismo de feição monopolista, "[...] pós-industrial, de hegemonia financeira e de globalização em escala transnacional". Tais posturas, identificadas pelo referido autor, se referem especificamente ao papel do Estado, ao controle dos gastos e controle da moeda, à relação Estado-sindicatos e ao estímulo à taxa de lucros das empresas:

a) restrição ao poder 'excessivo' do movimento operário e do sindicalismo, pressionando as empresas por salários e o Estado por políticas sociais; b) manutenção do Estado forte apenas para conter os sindicatos e controlar a moeda; c) no mais, minimização 
do Estado quanto a investimentos na economia e em política social; d) disciplina orçamentária; e) restauração da taxa 'natural' de desemprego e recriação do 'exército de reserva' de trabalhadores; f) estabilidade monetária; g) restauração da taxa de lucro das empresas restituídas à competitividade via produtividade (CASTANHO, 2009, p. 28).

Castanho (2009), por conseguinte, aponta para o redimensionamento do papel do Estado a partir dos ajustes neoliberais e do avanço do processo de Globalização, atingindo os países centrais e a periferia do capitalismo, como no caso da América Latina.

No caso do estudo de Rodriguez (2009), que trata da questão do processo de Globalização das políticas públicas no âmbito da América Latina, observa-se que as políticas educativas e reformas nos sistemas nacionais de educação, sob a influência do projeto político globalizante e neoliberal, passaram a desempenhar um papel relevante no sentido de legitimar a nova função e configuração subsidiária do Estado, num contexto de expansão dos setores privatistas, que passaram a ter maior participação na área educacional. Disso resultou a incorporação de novos paradigmas, que passaram a ser aplicados nos sistemas educacionais, oriundos da prática de gerenciamento empresarial e do setor privado.

\begin{abstract}
A década de 1990 caracteriza-se por uma tendência de modernizar a gestão dos sistemas de educação pública, oferecer iguais oportunidades de acesso a uma educação de "qualidade com "equidade" e "eficiência" para todos, fortalecer a profissão docente, aumentar os investimentos em educação e adequar os sistemas nacionais de educação pública às necessidades do mercado (RODRIGUEZ, 2009, p. 220).
\end{abstract}

A referida autora destaca que essas "[...] reformas educacionais têm-se apoiado em quatro eixos fundamentais: a gestão, a equidade e qualidade, a capacitação dos professores e o financiamento". (GAJARDO, 1999 apud RODRIGUEZ, 2009, p. 220).

No caso específico dos países da América Latina, o estudo de Rodriguez (2009, p. 221) mostra a expansão das reformas educacionais em consonância com o avanço do ideário neoliberal nesta região: 
A maioria dos países da América Latina modificou as leis de educação, objetivando "reorganizar o sistema educativo" e torna-lo coerente com o projeto neoliberal global. Por exemplo, a Argentina promulgou em 1993 a Lei Federal de Educação. Do mesmo modo, o Chile - que muito cedo emoldou o sistema educativo aos "tempos modernos" - sancionou em 1990 a Lei Orgânica Constitucional; o México, em 1993, sancionou a Lei Geral de educação; a Colômbia, em 1994, sancionou a Lei Geral de Educação; também o Brasil promulgou uma Lei de Diretrizes e Bases (LDB), em 1996, entre outros.

Por recomendação dos organismos internacionais, os governos dos diversos países da região procuraram melhorar a cobertura dos sistemas educacionais, especialmente no que se refere "[...] ao aumento da matrícula escolar para o ensino fundamental” (RODRIGUEZ, 2009, p. 221). Estes organismos internacionais preconizam o desenvolvimento econômico para a região a partir de sua relação com a globalização.

As recomendações dos documentos dos organismos internacionais têm focalizado a necessidade de oferecer condições materiais para assegurar 0 processo de democratização no continente e evitar o aumento do número de pobres e excluídos como consequência da radicalização da "globalização" econômica, o que aponta a importância do desenvolvimento econômico na construção de uma sociedade com equidade (RODRIGUEZ, 2009, p. 221).

A questão da equidade aparece frequentemente como conceito nas legislações de reformas educacionais ocorridas nos países da região (Argentina, México, Colômbia, Brasil). Tal conceito surgiu nas reformas dos anos de 1990, em substituição ao conceito de igualdade:

Em verdade, até a década de 1980 as lutas sociais eram pela defesa da igualdade e gratuidade na educação. Entretanto, os reformadores dos anos de 1990 assumiram uma retórica que substituiu a noção de igualdade pela equidade, sendo que este conceito só serve como meio para justificar as desigualdades, dado que permite a introdução de regras utilitárias de conduta que correspondem à desregulação do Direito, possibilitando o tratamento diferenciado para os diferentes setores sociais (RODRIGUEZ, 2009, p. 223). 
A qualidade da prestação do serviço educacional tornou-se outro importante eixo das reformas educacionais implementadas na América Latina tendo vinculação direta com a política de descentralização:

A "descentralização, a desregulação e a privatização dos serviços sociais" foram os instrumentos principais para melhorar a qualidade da prestação, mas também representaram um recurso de caráter econômico e político. As diferentes administrações centrais iniciaram uma redução de gastos e passaram a responsabilidade do setor educacional para os demais entes federados, deixando muitas vezes, de financiar adequadamente esse processo (RODRIGUEZ, 2009, p. 224).

Outro eixo fundamental relacionado às reformas educacionais ocorridas nos países da América Latina, diz respeito à questão da avaliação. As "[...] reformas educacionais nesses países apontam como eixos a qualidade e a avaliação, para assegurar a inserção dos sujeitos na sociedade e no mundo do trabalho de forma mais eficiente" (RODRIGUEZ, 2009, p. 225). Logo, manifestase um padrão geral dessas legislações educacionais no que se refere ao eixo da avaliação:

[...] a avaliação dos sistemas nacionais de ensino tem um objetivo de caráter punitório e classificatório. As instituições educativas são hierarquizadas, seguindo critérios eficienticistas, apesar de a avaliação ser apresentada como uma estratégia de melhoramento da qualidade de ensino (RODRIGUEZ, 2009, p. 226).

Convém ainda lembrar o aspecto da capacitação dos professores inserido no eixo avaliação. Nesse sentido, Rodriguez (2009, p. 226) ressalta esforços no sentido de medir a competitividade, tanto do sistema educacional, quanto de seus membros, incluindo aí mecanismos avaliativos tais como, "provas periódicas de idoneidade acadêmica e atualização pedagógica e profissional para os educadores", como ocorre no Sistema Nacional de Avaliação da Educação, em funcionamento na Lei Geral de Educação colombiana.

Em termos de avaliação dos ganhos e perdas da educação na América Latina sob a hegemonia dos ajustes econômicos neoliberais, o estudo de Rodriguez (2009, p. 227) aponta para a permanência do atraso e da exclusão: 
Durante a década de 1990, as reformas do Estado (econômicas, educativas, previdenciárias, trabalhistas, institucionais, entre outras) foram apresentadas especialmente pelos governos e organismos internacionais, como panaceias para todos os males. [...] Apesar dos avanços obtidos, os sistemas educacionais ainda não conseguem superar 0 atraso, tanto no rendimento escolar quanto na oferta de maiores oportunidades para amplos setores da sociedade latino-americana. Enfim, o setor educativo ainda é altamente excludente, já que $40 \%$ dos alunos abandonaram a escola antes de finalizar a educação básica.

No caso específico do Brasil, as reformas educacionais inspiradas nas diretrizes do projeto político global e no ajuste neoliberal ocorreram de forma mais sistemática ao longo dos dois governos de Fernando Henrique Cardoso.

Tratava-se de efetivar o ajuste recomendado pelos organismos internacionais mediante as políticas de desregulamentação, descentralização e privatização. Para isso era preciso reformar o Estado, definindo como sua função básica dar garantias às exorbitantes taxas de lucro do capital, internacional e nacional a ele associado, e, como consequência, mutilar os direitos sociais. Manteve, durante os oito anos de mandato o mesmo ministro da Fazenda, Pedro Malan - um competente quadro técnico brasileiro, até então trabalhando nos organismos internacionais (FRIGOTTO, 2006, p. 44).

Inspirado na lógica do mercado e disseminada pelos organismos internacionais, verifica-se a reafirmação e consolidação, na esfera das políticas públicas educacionais, do ideário do Estado Gerencialista, que se guia pelos princípios de racionalização e gestão de recursos, produtividade, avaliação, metas e objetivos.

Os discursos internacionais repetiam incansavelmente dois bordões: a) a importância da educação básica (no Brasil, reduzida à escola fundamental) para o novo padrão de desenvolvimento dos países periféricos e b) a necessidade de o Estado tornar-se menos provedor de financiamento e mais indutor de qualidade, por meio de diversos mecanismos de controle, tais como avaliações externas do sistema e a convocação dos pais e da sociedade para participação tanto do financiamento quanto da gestão escolar [...] Na verdade, o projeto visava a transformar as relações entre os sujeitos da cena escolar de forma que os pais e alunos se tornassem clientes e os professores e gestores assumissem o papel de prestadores de serviços, inserindo, assim, na escola a lógica do mercado (ZIBAS, 2005, p. 1070). 
Em síntese, sob a inspiração dos paradigmas do neoliberalismo e do capitalismo mundializado, é possível depreender que noções como capital humano, descentralização, equidade, avaliação, empregabilidade e gerencialismo, foram introduzidas na concepção e operacionalização das políticas públicas de Educação e de qualificação profissional, como no caso específico do PRONATEC.

\section{O PRONATEC e a qualificação voltada para empregabilidade}

O ciclo do novo desenvolvimentismo dos governos petistas contribuiu para criar novas demandas relacionadas à formação profissional para o atendimento do setor produtivo nacional. Logo, a justificativa para a criação do PRONATEC, além do interesse político governamental, veio do setor empresarial, uma vez que o discurso a respeito da carência de mão de obra qualificada ganhou força no país:

\footnotetext{
Legitimou-se o Programa para o enfrentamento de um "problema" brasileiro, disseminado pelos meios empresariais, reforçado pelo governo e aceito por parte da sociedade civil: o da falta de mão de obra qualificada, como uma das causas principais do desemprego, desviando-se do real problema da baixa escolaridade dos trabalhadores brasileiros (SALDANHA, 2016, p. 187).
}

De acordo com Frigotto (2009), de tempos em tempos produz-se um vozerio reclamando do sistema educacional e de seus professores pela falta de profissionais qualificados, sendo que o mais recente surgiu ao final de 2007, em torno do Programa de Aceleração do Crescimento (PAC), cuja meta é o crescimento do Produto Interno Bruto (PIB) em aproximadamente 5\% ao ano. Daí surgiu a expressão apagão educacional, "para se referir ao déficit de trabalhadores qualificados demandados nessa conjuntura." (FRIGOTTO, 2009, p. 74-75).

Lançado no início do governo Dilma, o PRONATEC (Programa Nacional de Acesso ao Ensino Técnico e Emprego) pretendeu ofertar "milhões de vagas até 2014 para a qualificação técnica e profissional de trabalhadores e de alunos do ensino médio, intensificando a expansão e interiorização das redes federal, estadual e privada [...]" (SALDANHA, 2012, p. 6). 
Para a análise da dinâmica de concepção e implementação do PRONATEC, enquanto programa de massificação da qualificação profissional, observa-se que, mesmo tendo sido concebido em um período de crescimento econômico e de retomada da expansão da oferta de emprego, diretamente vinculado ao Neodesenvolvimentismo Lulo-petista, é possível identificar neste programa governamental uma nítida tendência: a qualificação para a empregabilidade. Por conseguinte, torna-se necessário discutir a relação sócio histórica entre empregabilidade e expansão do modo de organização toyotista.

O estudo de Alves (2007, p. 245) compreende o "[...] conceito de empregabilidade enquanto elemento ideológico disseminado pelo espírito do toyotismo". Por sua vez, o referido autor, caracteriza o toyotismo como sendo:

[...] o modo de organização do trabalho e da produção capitalista adequado à era das novas máquinas da automação flexível, que constituem uma nova base técnica para o sistema do capital, e da crise estrutural de superprodução, com seus mercados restritos" (ALVES, 2007, p. 246).

Caracterizado como um modo de organização do trabalho, o toyotismo tende a exigir para o seu desenvolvimento, como a nova lógica da produção capitalista, "novas qualificações do trabalho que articulam habilidades cognitivas e habilidades comportamentais" (ALVES, 2007, p. 248).

Alves (2007, p. 248), com base na classificação proposta por Teixeira (1998), esquematiza essas novas qualificações do trabalho subdividindo-as em: "novos conhecimentos práticos e teóricos; capacidade de abstração, decisão e comunicação; e qualidades relativas à responsabilidade, atenção e interesse pelo trabalho".

A análise de Alves (2007) considera que a noção de empregabilidade surgiu no cenário de transformações vinculadas a consolidação e desenvolvimento do toyotismo, tornando-se o centro de referência das diretrizes de formação profissional:

O conceito de empregabilidade é um dos conceitos significativos da lógica do toyotismo determinando o âmago das políticas de formação profissional. Ele tende a tornar-se um senso-comum nas ideologias de formação profissional no capitalismo global. Diz Pablo Gentili: "A empregabilidade se incorpora no senso comum 
como significado que contribui a estruturar, orientar e definir as opções (ou a falta de opções) dos indivíduos no campo educacional e no mercado de trabalho, tornando-se também ' $a$ ' referência norteadora, o 'dever ser' dos programas de formação profissional $e$, inclusive, das próprias políticas educacionais" (GENTILI, 1998 apud ALVES, p. 250).

Da mesma forma, a empregabilidade tornou-se uma importante peça na engrenagem de funcionamento do capital global e das diretrizes ideológicas dos diversos governos de tendência ideológica neoliberal e da socialdemocracia:

É por isso que a mundialização do capital tende a disseminar, como eixo estruturador de sua política de formação profissional, o conceito de empregabilidade, que aparece, com relativo consenso, nos discursos de neoliberais ou socialdemocratas, como requisito básico para superar a crise do desemprego (ALVES, 2007, p. 251).

O estudo de Alves (2007) também considera que o conceito de empregabilidade pode ser também traduzido como um novo redimensionamento da lógica do Capital Humano, adaptada ao novo ambiente do capitalismo mundializado (globalizado):

A nova lógica da mundialização do capital significaria não o abandono da teoria do capital humano, que se disseminou na "época de ouro" do capitalismo, tendo em vista que sua concepção individualista ainda é adequada à hegemonia neoliberal, mas uma nova tradução da teoria do capital humano. É o conceito de empregabilidade que irá apresentar a nova tradução da teoria do capital humano sob o capitalismo global: a educação ou a aquisição (consumo) de novos saberes, competências e credenciais apenas habilitam o indivíduo para a competição num mercado de trabalho cada vez mais restrito, não garantindo, portanto, sua integração sistêmica plena (e permanente) à vida moderna. Enfim, a mera posse de novas qualificações não garante ao indivíduo um emprego no mundo do trabalho (ALVES, 2007, p. 253).

Alves (2007) conclui a sua análise desmistificando a ideia de que a expansão da formação profissional, com vistas à qualificação do trabalhador, pode garantir emprego no contexto da economia mundializada e neoliberal:

A ampliação de novas qualificações, por meio da extensão massiva da formação profissional, ao invés de garantir emprego a todos e a todas, cria, por um lado, a possibilidade do capital 
afirmar (e perpetuar) a existência de homens e mulheres como instrumentalidades para si (como é o caso da lógica do treinamento profissional). Mas por outro lado, explicitar, de modo candente, as contradições do sistema sócio metabólico do capital (ALVES, 2007, p. 255-256).

No Brasil, o processo de reestruturação produtiva e a expansão do modo de organização toyotista ganharam impulso com a expansão do neoliberalismo no governo de FHC. No entanto, foi durante a década de 2000, sob efeito do neodesenvolvimentismo do governo de Lula, e apesar do crescimento das taxas de emprego, que a reestruturação produtiva avançou junto com o processo de precarização do trabalho e do emprego. Neste sentido, Alves (2014, p. 166) afirma que:

\begin{abstract}
Apesar da redução do desemprego e aumento da formalização no mercado de trabalho, preserva-se no Brasil neodesenvolvimentista, profundos traços de precariedade salarial historicamente estrutural no país, como, por exemplo, as altas taxas de rotatividade e crescimento das terceirizações (por exemplo, em 2000, o Brasil tinha cerca de 3 milhões de trabalhadores terceirizados; em 2013, tem cerca de 15 milhões e, segundo estimativas, em 2020, terá cerca de 20 milhões.
\end{abstract}

Assim, mesmo considerando que houve crescimento do emprego formal durante o governo de Lula, há que se considerar o fato de que o avanço da reestruturação produtiva em nosso país, ao longo da década de 2000, expandiu a forma de organização/produção toyotista. Da mesma forma, o perfil do mercado de trabalho nacional foi afetado pelo avanço da precariedade e das terceirizações. E qual o reflexo dessa deterioração e precarização do emprego/trabalho sobre as políticas de qualificação profissional, como no caso do PRONATEC?

Nesses tempos de Globalização e de reestruturação produtiva, segundo Del Pino (2002, p. 79), difunde-se no imaginário das classes trabalhadores a crença de que "[...] mediante as diferentes modalidades [...] de formação, todos se tornarão empregáveis. É ingênuo acreditar que é possível corrigir as distorções do mercado em função da qualificação dos trabalhadores e trabalhadoras". Sendo assim, para este autor a relação entre escola e qualificação funciona sob outra lógica: 
Não é a escola que define o posto que o homem ou a mulher irão ocupar na produção. Ao contrário, muitas vezes o lugar que a família do aluno ou da aluna ocupa na produção é que acaba levando o/a aluno/a para um determinado tipo de escola. Portanto, não é possível resolver a crise de emprego dentro da escola (DEL PINO, 2002, p. 79).

Dentro da lógica dominante do capital global/neoliberal, "[...] os desempregados é que ficam com a responsabilidade de buscar requalificação e reconversão profissional, a fim de tornarem-se empregáveis" (DEL PINO, 2002, p. 80). Na dinâmica da reestruturação produtiva, a escola assume o papel de disseminadora do discurso da empregabilidade:

No interior da escola e dos cursos de requalificação têm de ser desenvolvidas as relações que permitem fazer com que alunos/as e professores/as pensem e sintam que todos se tornarão empregáveis. O discurso da empregabilidade afirma que a requalificação pode gerar as condições de se chegar ao emprego (DEL PINO, 2002, p. 80).

A questão fundamental por trás do discurso da empregabilidade é que, no contexto da produção enxuta, com trabalho flexível e polivalente, inerentes à organização toyotista, não há emprego para todos os trabalhadores. Por isso, reforça-se a ideia da competitividade, pela qual "nem todos serão vencedores" no cenário de um mercado de trabalho competitivo, cabendo à escola a função de selecionar para o emprego (DEL PINO, 2002, p. 80-81).

Para Gentili (2013, p. 89), o aumento da pobreza, da desigualdade social e do desemprego, ligado às décadas de crise global, puseram fim à ideia de se pensar "[...] no mercado de trabalho, como uma esfera de expansão ilimitada, simplesmente porque nele não poderia haver espaço para todos". Consequentemente:

Educar para o emprego levou ao reconhecimento (trágico para alguns, natural para outros) de que se deveria formar também para o desemprego, numa lógica de desenvolvimento que transformava a dupla "trabalho/ausência de trabalho num matrimônio inseparável" (GENTILI, 2013, p. 89).

Para este autor, as décadas de crise global também produziram uma nova esperança diante da "[...] natureza estruturalmente excludente dos novos tempos: 
a empregabilidade" (GENTILI, 2013, p. 89). E a esperança da empregabilidade redimensionou o propósito das políticas educacionais:

Mais do que pensar a integração dos trabalhadores ao mercado de trabalho, o desenho das políticas educacionais deveria orientar-se para garantir a transmissão diferenciada de competências flexíveis que habilitem os indivíduos a lutar nos exigentes mercados laborais pelos poucos empregos disponíveis (GENTILI, 2013, p 89).

A ideia da empregabilidade também redimensiona o papel da escola, reduzindo-a a função de viabilizar e instrumentalizar a preparação da competência empregatícia dos alunos, que devem ser qualificados para o cenário de limitada inserção que o mercado oferece:

$\mathrm{Na}$ era do fim dos empregos, só a competência empregatícia flexível do indivíduo pode garantir acesso no mundo das relações laborais (RIFKIN, 1996). E essa competência deverá ser procurada na escola, embora não exclusivamente. Uma escola esvaziada de funções sociais, onde a produtividade institucional possa ser reconhecida nas habilidades que os seus clientesalunos disponham para responder aos novos desafios de um mercado altamente seletivo impõe (GENTILI, 2013, p. 89-90).

O que se observa nos programas de qualificação/requalificação profissional, tal qual o PRONATEC, é que tendem a formar para a empregabilidade, o que não garante o emprego e direciona para a informalidade e para funções e postos de trabalho precarizados.

No caso do PRONATEC, a sua criação foi justificada a partir da premissa de se promover a aproximação entre o processo de formação profissional e o mundo do trabalho. Por isso, na primeira versão do Guia PRONATEC FIC apresentada no Portal PRONATEC, foram disponibilizados "[...] 518 opções de cursos, distribuídos em 13 eixos tecnológicos, conforme suas características científicas e tecnológicas" (PORTAL PRONATEC, 2016). Também na referida apresentação, é anunciado que o MEC considera como finalidade/objetivo do Guia PRONATEC, contribuir "[...] para a consolidação de uma política pública que tem como objetivo principal aproximar o mundo do trabalho do universo da Educação" (PORTAL PRONATEC, 2016). 
O discurso governamental de Dilma Rousseff, durante a cerimônia de lançamento do PRONATEC, justificou a expansão da oferta de formação profissional, objetivando atender às demandas de crescimento da economia:

Estamos, hoje, próximos do pleno emprego e enfrentamos grande demanda de mão de obra qualificada. Demanda, muitas vezes, assimétrica porque, em alguns casos, falta mão de obra qualificada, em outros, sobra mão de obra sem a qualificação necessária derivada das nossas necessidades, da indústria, do comércio, dos serviços, enfim, do sistema produtivo [...]. Nesse sentido, eu lanço hoje aqui o Pronatec [...] (BLOG DO PLANALTO, 28/04/2011).

O esforço do Governo Federal seria no sentido de tornar o PRONATEC uma eficiente ponte de ligação entre a capacitação profissional da massa trabalhadora e os interesses do mercado capitalista de trabalho.

O Pronatec vai, portanto, ser um fator de organização da oferta de formação e capacitação profissional para todos os brasileiros e brasileiras. Esse programa, ele vai além da esfera do ensino médio e inclui diferentes vertentes de aprimoramento dos trabalhadores ativos e de articulação com o mercado de trabalho. (BLOG DO PLANALTO, 28/04/2011).

Não obstante o interesse governamental no sentido de garantir a eficiência da capacitação profissional via cursos do PRONATEC, devem ser considerados três princípios elementares desse programa governamental que comprometem a qualidade e o rendimento dos cursos ofertados: a) a noção de qualificação com foco nas competências; b) a predominância de cursos na modalidade concomitante; c) a predominância de cursos de curta duração.

O primeiro desses princípios tem a ver com a noção de qualificação com foco no desenvolvimento de competências. Consequentemente, a qualificação volta-se para a finalidade de garantir a empregabilidade:

A qualificação enquanto competência, se apresenta como proposta de formação para o desemprego. Uma qualificação que promove a criação de exército de trabalhadores de reserva, ao mesmo tempo que fomenta um novo mercado de consumo, por meio de cursos de qualificação técnica. A qualificação fragmentada dimensionalmente, foi reduzida apenas a uma dimensão técnica quando travestida pela noção de competências. Perdeu a sua dimensão social ao ser incorporada pela sociedade 
apenas como aquisição de noções técnicas (GERALDINO, 2015, p. 154).

Dessa forma, é possível afirmar que a predominância de cursos de 100, 200, 240 horas, presente no Guia PRONATEC de cursos FIC, segue a lógica de priorizar a aquisição de conhecimentos ou desenvolvimento de competências voltadas essencialmente para o "saber executar". Portanto, isso significa "[...] que além de diminuir os conhecimentos, é preciso apresentá-los de forma operacional, ou seja, que tenham um sentido imediato, isto é, que sejam úteis e práticos" (MAUÉS, 2009, p. 301). Ressalta-se que a maioria desses cursos FIC PRONATEC ofertados se vincula ao setor de prestação de serviços, notadamente em expansão nos tempos atuais de reestruturação produtiva, com significativa utilização de mão-de-obra flexível e terceirizada.

Quanto à manutenção da dualidade no ensino e da fragmentação por meio de cursos concomitantes, condensados no Guia PRONATEC de Cursos FIC, deve-se considerar que a concomitância tende a reforçar na prática cotidiana a dualidade, ensejando a fragmentação entre conhecimento geral e conhecimento específico:

\begin{abstract}
A oferta de cursos técnicos na forma concomitante é considerada como articulada ao Ensino Médio: os alunos realizam este em um estabelecimento de ensino público em determinado turno, mediante uma matrícula e, em outro turno e geralmente em instituição de ensino diferenciada, outra matrícula é efetuada para o curso técnico. A legislação educacional prevê convênio ou acordos de intercomplementaridade com planejamento e desenvolvimento de projeto pedagógico unificado para o $\mathrm{EM}$ e os cursos técnicos concomitantes. No entanto, de uma forma geral, o trabalho pedagógico conjunto não se desenvolve em torno de um projeto unificado, mas de currículos separados, realizados de forma que o conhecimento geral e o específico não se integram (GERALDINO, 2015, p. 185).
\end{abstract}

A predominância no PRONATEC de cursos sob o regime de concomitância é complementada pela disseminação, via Guia PRONATEC FIC, de cursos de curta duração. "A ênfase dada aos cursos de curta duração (Formação Inicial e Continuada) é, portanto, quase três vezes maior do que a quantidade de cursos de nível técnico" (JUNG; SILVA, 2014, p. 16). Por conseguinte, a qualidade desses cursos pode ser considera como duvidosa, servindo a outros interesses situados no campo da ideologia: 
A quase totalidade dos cursos de curta duração suscita a dúvida sobre o tipo de formação que está sendo oferecida para esse público em tão diminuta carga horária. Como é possível observar, o público-alvo dos cursos de curta duração são os jovens e os trabalhadores pouco escolarizados, uma vez que para cursar o nível técnico é preciso estar cursando ou concluído o ensino médio. Depreende-se disso que a formação oferecida para esse público aproxima-se mais de uma estratégia de manutenção do consenso em torno da ideologia dominante do que de fato, uma educação que vise superar as contradições de classe até aqui apontadas (JUNG; SILVA, 2014, p. 17).

No contexto de consenso mencionado pelas autoras em torno da ideologia dominante, poderíamos situar também os interesses empresariais no aumento do exército de reserva, com base na aquisição de trabalhadores minimamente treinados e adaptados aos postos de trabalho, nos quais são requeridas atitudes comportamentais pautadas em novos saberes e competências.

Ainda em relação à preferência dada aos cursos de curta duração, Costa (2015) considera o aspecto da formação essencialmente voltada para o treinamento, bem como para o atendimento da demanda específica por habilidades relacionadas à produção de bens e consumo. Em contrapartida, a porcentagem de cursos com carga horária mais elevada corresponde a menos de um terço do total de cursos ofertados no PRONATEC:

O que se verifica, no período de 2011 e 2013, é a oferta de 3.957.759 vagas na modalidade FIC (ver tabela 7), que têm como característica a sua curta duração, que varia de 160 a 400 horas. Assim, é possível afirmar que proposta do PRONATEC de concentrar a oferta de vagas em cursos de curta duração se opõe aos interesses da classe trabalhadora por desenvolver atividades centradas no treinamento. Esta, no entanto, é uma tendência que se deveu a generalização do emprego diretamente produtivo da ciência, razão pela qual são estimuladas "atividades de formação técnico-profissional que visam ao desenvolvimento de habilidades específicas voltadas para sua aplicação direta na produção de bens e, mais contemporaneamente, de serviços" (NEVES e PRONKO, p. 28, 2008) [...]. Em termos percentuais, considerando o total de vagas do PRONATEC previstas para o período de 2011 a 2013, constata-se que $70,05 \%$ destas concentraram-se em cursos na modalidade FIC [...]. Por ouro lado, foram ofertadas apenas $29,95 \%$ ou 1.665 .478 vagas em cursos técnicos, cuja duração mínima é de pelo menos 800 horas (COSTA, 2015, p. 95). 
No mesmo sentido, Saldanha (2016) anuncia que a preferência de investimentos por parte do Governo Federal recai sobre os cursos da modalidade FIC, no geral de curta duração e de formatação concomitante, majoritariamente oferecidos pelo Sistema S em prejuízo da oferta de cursos técnicos por parte da rede federal de ensino:

[...] a oferta inicial dos cursos técnicos no PRONATEC correspondeu a menos de um terço em relação ao total dos cursos de qualificação, os denominados cursos de Formação Inicial e Continuada (FIC). Quase metade destes foi ofertada pelo Sistema S, voltados para a formação de mão de obra para o mercado. A expansão real do Programa, até 2014, deu-se nos cursos FIC, que correspondem ao dobro das matrículas dos cursos técnicos (BRASIL/MEC/SIMEC/SETEC, 2014), dando a continuidade à tendência histórica de formação para o trabalho simples no Brasil [...] (SALDANHA, 2016, p. 292).

Há que se ressaltar a ostensiva presença das instituições que compõem o Sistema S como ofertantes de vagas no PRONATEC, tanto na transferência de recursos públicos para a iniciativa privada para formar a classe trabalhadora quanto na definição da concepção de formação proporcionada aos estudantes, ancorada na narrativa da empregabilidade e na teoria do capital humano.

Essa dinâmica de funcionamento do PRONATEC, de participação crescente do setor privado e com base na formatação de cursos concomitantes e de curta duração, faz parte de uma lógica maior e mais generalizante das políticas públicas e programas governamentais dos dias atuais, voltados para a reprodução da empregabilidade e da precariedade dos postos de trabalho, reproduzindo preceitos do neoliberalismo e das tendências hegemônicas do capitalismo global.

\section{Considerações Finais}

É possível afirmar que o PRONATEC, inserido no contexto de predominância do modelo de acumulação flexível, de reestruturação produtiva e de mundialização/globalização do capital e de hegemonia neoliberal, foi concebido como alternativa imediatista de resposta às novas demandas do ciclo de expansão econômica neodesenvolvimentista, iniciado no governo Lula, e que entrou em crise no final do primeiro governo de Dilma Rousseff. Também se deve 
considerar que o PRONATEC representa a reafirmação do receituário neoliberal, já que reproduz, em sua dinâmica de concepção e funcionamento, os preceitos de empregabilidade e de dualidade no ensino, por meio da estruturação de cursos sob o regime de concomitância. Sendo assim, prioriza a oferta de cursos de curta duração, que tendem a fornecer formação precária para postos de trabalho precarizados, reduzindo as perspectivas de formação de cidadãos críticos, bem como o acesso democrático ao amplo conhecimento. Em contrapartida, privilegia essencialmente a geração e reprodução de uma grande massa de produtoresconsumidores, para que se encaixem no modelo vigente de organização toyotista e de capitalismo neoliberal.

\section{Referências}

ALVES, Giovanni. Reestruturação produtiva, novas qualificações e empregabilidade. In: ALVES, Giovanni. Dimensões da reestruturação produtiva: ensaios de sociologia do trabalho. Londrina: Práxis, 2007. Disponível em: <http://giovannialves.org/Capitulo\%2010_texto.pdf>. Acesso em: 11 ago. 2016.

ALVES, Giovanni. Trabalho e desenvolvimento: choque de capitalismo e nova degradação do trabalho no Brasil. Bauru: Canal 6, 2014.

BRASIL. Lei no 12.513, de 26 de outubro de 2011. Institui o Programa Nacional de Acesso ao Ensino Técnico e Emprego (Pronatec); altera as Leis no 7.998, de 11 de janeiro de 1990, que regula o Programa do Seguro-Desemprego, o Abono Salarial e institui o Fundo de Amparo ao Trabalhador (FAT), no 8.212, de 24 de julho de 1991, que dispõe sobre a organização da Seguridade Social e institui Plano de Custeio, no 10.260, de 12 de julho de 2001, que dispõe sobre o Fundo de Financiamento ao Estudante do Ensino Superior, e no 11.129, de 30 de junho de 2005, que institui o Programa Nacional de Inclusão de Jovens (ProJovem); e dá outras providências. Diário Oficial da União, 27 out. 2011c. Disponível em: <http://www.planalto.gov.br/ccivil_03/_ato2011-2014/2011/lei/112513.htm>.

Acesso em: 18 mar. 2016.

BRASIL. MEC. Portaria $n^{\circ} 1.568$, de 3 de novembro de 2011d. Aprova o Guia Pronatec de Cursos de Formação Inicial e Continuada. Disponível em:

$<$ http://pronatec.mec.gov.br/images/stories/pdf/portaria_1568.pdf>. Acesso em: 22 mar. 2015.

BRESSER-PEREIRA, Luiz Carlos. A quase estagnação brasileira e sua explicação novo-desenvolvimentista. In: BARBOSA, Nelson [et al]. Indústria e desenvolvimento produtivo no Brasil. 1. ed. Rio de Janeiro: Elsevier: FVG, 2015. 
BLOG DO PLANALTO. Discurso da Presidenta da República, Dilma Rousseff, durante cerimônia de lançamento do Programa Nacional de Acesso ao Ensino Técnico e ao Emprego. 2011.2 Disponível em: $<$ http://www2.planalto.gov.br/acompanhe-o-planalto/discursos/discursos-dapresidenta/discurso-da-presidenta-da-republica-dilma-rousseff-durante-cerimoniade-lancamento-do-programa-nacional-de-acesso-ao-ensino-tecnico-e-aoemprego >. Acesso em: 29 abr. 2016.

BLOG MEC/PRONATEC. Guia Pronatec de cursos FIC. Disponível em: http://portal.mec.gov.br/pronatec/catalogos>. Acesso em: 15 nov. 2016.

COSTA, Fernanda Cosme da. O Programa Nacional de Acesso ao Ensino Técnico e Emprego (PRONATEC) e a educação escolar da classe trabalhadora. 2015. 140 f. Dissertação (Mestrado Profissional em Educação Profissional em Saúde) - Escola Politécnica de Saúde Joaquim Venâncio, Fundação Oswaldo Cruz, Rio de Janeiro.

DEL PINO, Mauro. Política educacional, emprego e exclusão. In: GENTILI, Pablo; FRIGOTTO, Gaudêncio (Orgs.). A cidadania negada: políticas de exclusão na educação e no trabalho. 3. ed. - São Paulo: Cortez; Buenos Aires: CLACSO, 2002.

FRIGOTTO, Gaudêncio. Educação e a crise do capitalismo real. 5. ed. - São Paulo: Cortez, 2003.

. Política e gestão educacional na contemporaneidade. In: FERREIRA, E.B.; OLIVEIRA, D.A. (Orgs.). Crise da escola e políticas educativas. Belo Horizonte: Autêntica, 2009.

GAMBOA, Silvio Sánchez. A Globalização e os desafios da educação no limiar do novo século: um olhar desde a América Latina. In: LOMBARDI, José Claudinei (Org.). Globalização, pós-modernidade e educação: história, filosofia e temas transversais. 3. ed. - Campinas: Autores Associados; Caçador: UnC, 2009.

GENTILI, Pablo. Educar para o desemprego: a desintegração da promessa integradora. In: FRIGOTTO, Gaudêncio (org.). Educação e crise do trabalho. 12. ed. - Petrópolis: Vozes, 2013.

GERALDINO, Gustavo Cesar Lopes. Políticas públicas de qualificação para o trabalho: o PRONATEC em discussão. 2015. 176 f. Dissertação (Mestrado em Educação) - Universidade Estadual de Maringá, Maringá.

GIAMBIAGI, Fábio. Rompendo com a ruptura: o governo Lula (2003-2010). In: GIAMBIAGI, Fábio et al. Economia brasileira contemporânea [1945-2010]. 2. ed. Rio de Janeiro: Elsevier, 2011.

GONÇALVES, Reinaldo. Desenvolvimento às avessas: verdade, má-fé e ilusão no atual modelo brasileiro de desenvolvimento. Rio de Janeiro: LTC, 2013. 
JUNG, Pâmela Regina; SILVA, Mariléia Maria da. A Qualificação profissional dos jovens nos moldes da Teoria do Capital Humano repaginada: apontamento sobre o PRONATEC. In: X ANPED SUL, Florianópolis, outubro de 2014. Disponível em: <http://xanpedsul.faed.udesc.br/arq_pdf/887-1.pdf>. Acesso em: 28 ago. 2016.

LIMA Filho, Domingo Leite. A feliz aliança entre educação, desenvolvimento e mobilidade social: elementos para uma crítica à nova roupagem do capital humano. Trabalho e Educação, Belo Horizonte: UFMG, v. 12, n. 2, p. 61-80, jul./dez. $2003 . \quad$ Disponível em: $<$ https://seer.ufmg.br/index.php/trabedu/article/view/7351/5706>. Acesso em: 22 fev. 2016.

MAUÉS, Ogaíse Cabral. O papel da escola na construção dos saberes e os limites da noção de competências. In: FERREIRA, E.B.; OLIVEIRA, D.A.(Orgs.). Crise da escola e políticas educativas. Belo Horizonte: Autêntica, 2009.

SALDANHA, Letícia de Luca Wollmann. O PRONATEC e a relação ensino médio e educação profissional. In: IX Seminário de Pesquisa da Região Sul (ANPEDSUL), $2012 . \quad$ Disponível em: <http://www.ucs.br/etc/conferencias/index.php/anpedsul/9anpedsul/paper/viewFile /1713/141>. Acesso em: 10 jun. 2014.

SALDANHA, Letícia de Luca Wollmann. Razões da permanência, abandono e reprovação de jovens alunos no PRONATEC: democratização da educação profissional técnica de nível médio? In: RIBEIRO, Mônica; OLIVEIRA, Rosângela Gonçalves de (Orgs.). Juventude e Ensino Médio: sentidos e significados da experiência escolar. Curitiba: UFPR/Setor de Educação, 2016.

ZIBAS, Dagmar M. L. Refundar o ensino médio? Alguns antecedentes e atuais desdobramentos das políticas dos anos de 1990. Educ. Soc., Campinas, vol. 26, n.92, Especial - Out. 2005. Disponível em: $<$ http://www.scielo.br/pdf/es/v26n92/v26n92a16.pdf>. Acesso em 15 jan. 2018.

Recebido em: 27 de fevereiro de 2018.

Aprovado em: 23 de abril de 2018.

Publicado em: 21 de novembro de 2018. 